\title{
A longitudinal survey of African swine fever in Uganda reveals high apparent disease incidence rates in domestic pigs, but absence of detectable persistent virus infections in blood and serum
}

Denis Muhangi ${ }^{1 *}$, Charles Masembe ${ }^{2}$, Ulf Emanuelson ${ }^{3}$, Sofia Boqvist ${ }^{4}$, Lawrence Mayega ${ }^{5}$, Rose Okurut Ademun ${ }^{6}$, Richard P Bishop ${ }^{7}$, Michael Ocaido ${ }^{1}$, Mikael Berg ${ }^{4}$ and Karl Ståhl ${ }^{4,8}$

\begin{abstract}
Background: African swine fever (ASF) is a fatal, haemorrhagic disease of domestic pigs, that poses a serious threat to pig farmers and is currently endemic in domestic pigs in most of sub-Saharan Africa. To obtain insight into the factors related to ASF outbreaks at the farm-level, a longitudinal study was performed in one of the major pig producing areas in central Uganda. Potential risk factors associated with outbreaks of ASF were investigated including the possible presence of apparently healthy ASF-virus (ASFV) infected pigs, which could act as long-term carriers of the virus. Blood and serum were sampled from 715 pigs (241 farms) and 649 pigs (233 farms) to investigate presence of ASFV and antibodies, during the periods of June-October 2010 and March-June 2011, respectively. To determine the potential contribution of different risks to ASF spread, a questionnaire-based survey was administered to farmers to assess the association between ASF outbreaks during the study period and the risk factors.
\end{abstract}

Results: Fifty-one (21\%) and 13 (5.6\%) farms reported an ASF outbreak on their farms in the previous one to two years and during the study period, respectively. The incidence rate for ASF prior to the study period was estimated at 14.1 per 100 pig farm-years and 5.6 per 100 pig farm-years during the study. Three pigs tested positive for ASFV using real-time PCR, but none tested positive for ASFV specific antibodies using two different commercial ELISA tests.

Conclusions: There was no evidence for existence of pigs that were long-term carriers for the virus based on the analysis of blood and serum as there were no seropositive pigs and the only three ASFV DNA positive pigs were acutely infected and were linked to outbreaks reported by farmers during the study. Potential ASF risk factors were present on both small and medium-scale pig farms, although small scale farms exhibited a higher proportion with multiple potential risk factors (like borrowing boars for sows mating, buying replacement from neighboring farms without ascertaining health status, etc) and did not implement any biosecurity measures. However, no risk factors were significantly associated with ASF reports during the study.

Keywords: African swine fever (ASF), Epidemiology, Incidence rate, Risk factors, Smallholder farmers

\footnotetext{
*Correspondence: mdenis@covab.mak.ac.ug

${ }^{1}$ Department of Wildlife and Aquatic Resources, College of Veterinary

Medicine, Animal Resources and Biosecurity, Makerere University, P. O. Box

7062, Kampala, Uganda

Full list of author information is available at the end of the article
}

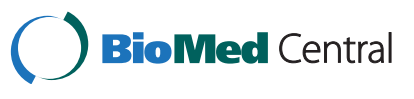

(c) 2015 Muhangi et al.; licensee BioMed Central. This is an Open Access article distributed under the terms of the Creative Commons Attribution License (http://creativecommons.org/licenses/by/4.0), which permits unrestricted use, distribution, and reproduction in any medium, provided the original work is properly credited. The Creative Commons Public Domain Dedication waiver (http://creativecommons.org/publicdomain/zero/1.0/) applies to the data made available in this article, unless otherwise stated. 


\section{Background}

ASF is a fatal, haemorrhagic, viral infection of pigs caused by ASFV, an Asfivirus and the only member of the family Asfarviridae, which poses a threat to both commercial and smallholder pig farmers. It is currently endemic in at least 26 countries in sub-Saharan Africa [1] as well as on the Island of Sardinia (Italy), the Caucasus, parts of Russia, and in eastern part of the European Union where it was introduced in 2014. The disease can have a severe socio-economic impact on people's livelihoods, food security and both regional and international trade [2].

In sub-Saharan Africa (SSA), the importance of pig production to food security and household incomes is growing and the numbers of pigs on the continent have increased almost threefold during the last decades $[1,3,4]$. This is as a result of a steady increase in demand for animal protein by a growing middle-class. Since most of the increase is taking place in smallholder or backyard husbandry systems with low levels of biosecurity, the growth of the sector creates disease prevention and control challenges [5]. A larger and denser pig population on the continent coupled with an increase in movements of pigs and pig products, as well as people, is most likely the main factor responsible for the upsurge of ASF in many new areas in SSA $[1,5]$. The current ASF situation, with the rising numbers of endemically infected countries in SSA and Europe and more ASFV circulating globally constitutes a serious threat to ASFfree countries in Europe as well as Asia [6]. Further spill-over events from either Africa, the Caucasus or eastern Europe, as a result of increased movement of people and pig products, could lead to huge losses in international trade [5].

To date, three cycles involved in the transmission of ASF have been identified: the sylvatic cycle involving circulation of the virus between warthogs (Phacochoerus africanus) and soft ticks of the genus Ornithodoros, the tick-to-domestic pig cycle and lastly the domestic pigto-pig cycle [7]. The sylvatic cycle is present in eastern and southern Africa and here, historically, it is considered the main source of outbreaks of ASF in domestic pigs [8]. Today, however, the disease has become endemic in the growing domestic pig populations in several countries in the region, including Uganda, with outbreaks mainly associated with movements of pigs and pig products [1]. A sufficiently large population provides a constant supply of naïve pigs, and is, in the low biosecurity setting dominating in SSA, therefore likely to allow maintenance of ASF without involvement of the sylvatic host. The presence of apparently healthy long-term carriers possibly shedding the virus as suggested by some authors [9-12] would further facilitate the indefinite perpetuation of the disease.
The aim of the study was to investigate the factors related to ASF outbreaks at farm-level, and maintenance of the disease in the domestic pig population, including the existence and possible role of apparently healthy ASFV infected pigs, which could act as long-term carriers of the virus.

\section{Results}

\section{Farms sampled}

A total of 715 pigs ( 241 farms) and 649 pigs (233 farms) were sampled at the first and second sampling time points, respectively. Despite one of the study's conditions being that the farmers were to keep pigs until the next visit for follow up, eight of the farmers were not available at the second sampling point. Of these, two had sold off all pigs as a result of suspected ASF on the farm. The rest either sold them off for reasons other than ASF or they were not available for interview at the second visit.

Four hundred seventy six (476) pigs on 161 farms from Masaka and 239 pigs on 80 farms were sampled from Rakai during the first sampling point (Fig. 1). Four hundred twenty two (422) pigs on 154 farms and 227 pigs on 79 farms from Masaka and Rakai, respectively were sampled during the second phase of the study (Fig. 1).

\section{Awareness and knowledge of ASF}

The vast majority of the farmers were aware of ASF and could correctly describe two to three of the most important clinical signs. ASF was generally described as a disease that has no cure or vaccine, and that kills large numbers of pigs fast. Pigs develop high fever, lose appetite and die within two days. Discoloration of the skin (turning blue or red) is also mentioned.

\section{Incidence of ASF}

A total of 51 (21\%) farms reported having had incidences of ASF one to two years preceding the first visit. Between the first and second visits, 13 (5.6\%) farms reported having experienced an outbreak of ASF (Fig. 1), with mortalities between 12-100\% (median $66 \%$ ). In one of the farms, ASF was confirmed as positive by RTPCR in two out of the three pigs sampled. The incidence rates for ASF were estimated at 14.1 per 100 pig farmyears $(95 \%$ CI 7.7;23.5) and 5.6 per 100 pig farm-years (95\% CI 2.2;13.1) for the periods prior to and between the two visits, respectively. The difference in estimated incidence rates for the two periods was not statistically significant $(P$-value $=0.10)$.

\section{ASFV DNA and antibody detection}

Genomic DNA was successfully extracted from all the pooled samples. All the pigs in the initial round tested 


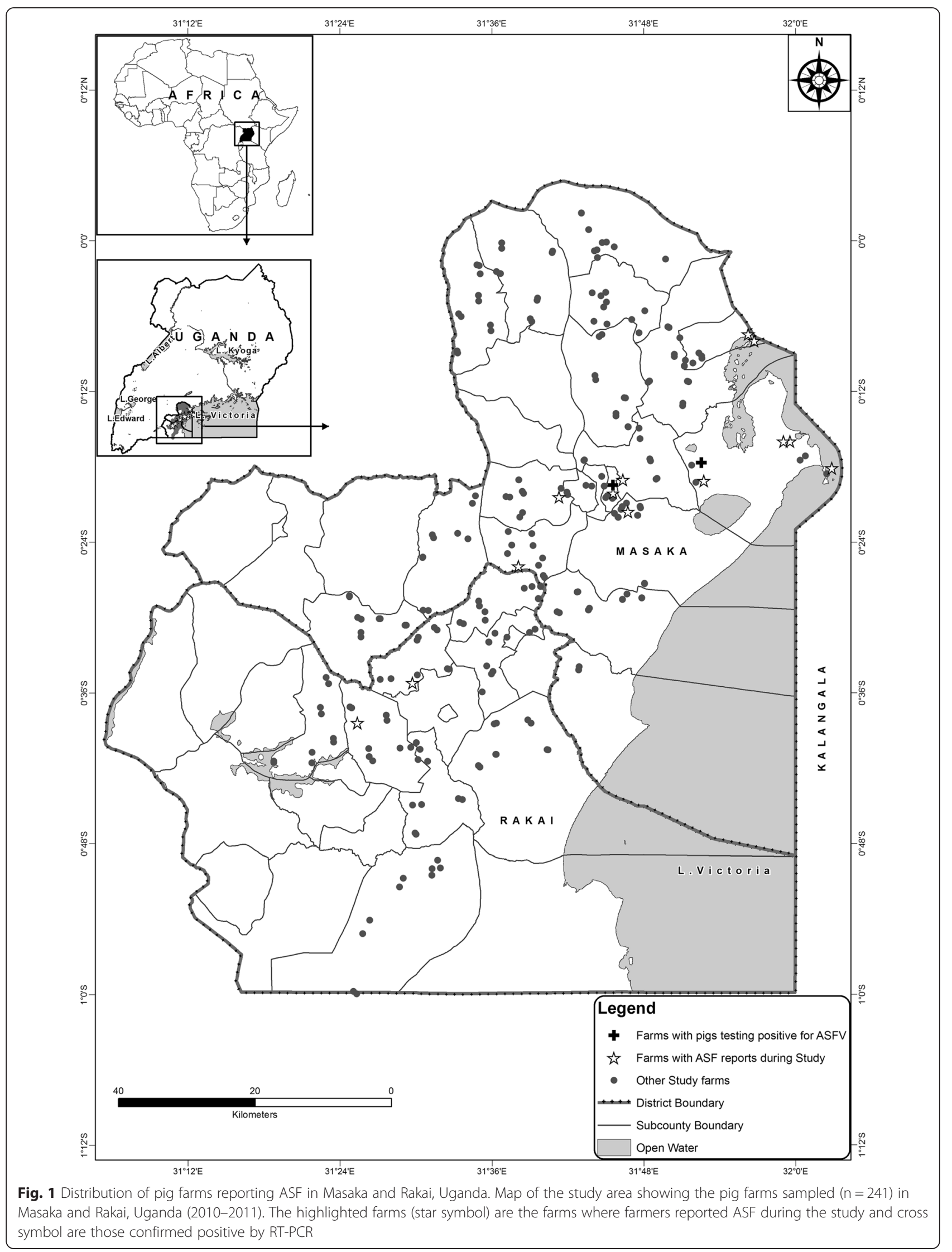


negative for ASFV using RT-PCR. In the second sampling round, three pigs from two different farms tested positive (Ct values: 21.2, 37.9 and 38.8) (Fig. 1). These two farms were both located in areas where outbreaks of ASF had occurred. The corresponding true prevalences were estimated at $0 \%(95 \% \mathrm{CI} 0 ; 0.6)$ and $0.5 \%(95 \%$ CI $0.1 ; 1.5)$ at the first and the second sampling-points, respectively.

Twenty-three sera were either antibody positive or doubtful on the first run using INGENASA. However, a re-run on all the positive sera $(n=5)$ using INGENASA and SVANOVIR ASFV-Ab ELISA tests, and all doubtful sera $(n=18)$ using SVANOVIR, resulted in none of the samples being positive for ASF antibodies with either of the two different ELISA tests used.

\section{Differential diagnosis}

In total 239 samples were analyzed for presence of antibodies and nucleic acids specific to CSFV and PRRSV, respectively. All samples tested negative for CSF and PPRS in ELISA as well as in RT-PCR. This is also reported as preliminary results in a student thesis [13].

\section{Herd categories and risk factors}

The numbers of farms according to size were 185 $(78.7 \%)$ and 50 (21.3\%) for small and medium-scale pig farms, respectively, with six missing values at first sampling. At second sampling, the numbers were 179 (76.5 \%) and 49 (20.9\%) farms for the small-scale and medium-scale farms, respectively. Results from the questionnaire are presented in Tables 1 and 2. There were more farms with high proportions of improved breeds compared to those with local breeds of pigs. There were comparably more farms that borrowed boars from other farms for mating than those that did not, more farms sourcing replacement stock from neighbouring farms than those obtaining replacement stock generated on their own farms. For small-scale farms, those with none of the biosecurity measures (fences, controlled access to pens, foot-baths) were greater in number than those with at least one of the biosecurity measures in place (Table 1). The medium-scale farms had more farms that had at least one biosecurity measure than those that had none (Table 2). Feeding swill was common in both small and medium-scale farms.

The risk factor analysis of reported outbreaks of ASF during the study period did not produce any statistically significant predictors (Table 3).

\section{Discussion}

ASF has had a global upsurge, and has been reported in at least 26 countries in SSA alone during the last few years [1]. The disease is considered endemic in domestic pig populations in many of these countries, but data on incidence rates is scarce. In our study population, more than $5 \%$ of the farms reported incursions of ASF during the one-year study period (ASF between). Albeit based on farmer reports, this gives a rough estimate of the incidence rate of the disease in the population. Nine of the 13 affected farms were located in areas in which we confirmed ASF during this period (data not shown), supporting the accuracy of the reports. The estimated incidence rate for the period prior to the study (ASF prior) was numerically higher compared to ASF between, but the difference was not statistically significant. This latter estimate is likely to be less accurate than for ASF between, because it includes farmers' perception of time since last experience of ASF and was therefore excluded from analysis of risk factors. Record keeping among smallholder pig farmers in the region is generally poor [14].

Important differential diagnoses to ASF such as CSF and PRRS, have never been reported in Uganda or in neighboring countries [15], and our study also failed to demonstrate presence of or exposure to these diseases in the study population. Moreover, during the period 2010-2012, we investigated around 50 reported outbreaks of suspected ASF in Uganda, including several in the study area, and in all but two ASF was confirmed, clearly suggesting ASF as the most prevalent cause of disease with high mortality in pigs in the region. All samples $(n=80)$ from four of these outbreaks, including the two in which ASF was not confirmed, were also tested for CSF and PRRS with negative results in all but one sample which was weakly positive on PRRS ELISA [13]. Given that only one out of a total of 319 samples tested positive for PRRS antibodies, the weakly positive result was interpreted as false positive. Our case definition was based on farmer reports of outbreaks of disease with clinical signs suggestive of, but not pathognomonic to ASF, which could imply a risk for misclassification. However, given the level of awareness of ASF demonstrated by the farmers, the very dramatic clinical signs typically associated with ASF, and the probable absence of the most important differential diagnoses in the study population, this risk is considered low.

Bacterial diseases such as erysipelas, which do occur in the study area, are also often mentioned as differential diagnoses to ASF, due to similar clinical signs in the individual animal. However, in contrast to ASF, erysipelas is a curable disease that most often affects individual animals rather than entire herds, and was therefore not considered in the study.

Several authors have reported high prevalences of ASF, based on detection of ASFV DNA in blood, serum and/ or tissues using PCR in apparently healthy and often seronegative domestic pigs originating from locations 
Table 1 Risk factors for small-scale farms for ASF reports between first and second sampling $(n=179), 2010-2011$

\begin{tabular}{|c|c|c|c|c|c|}
\hline \multirow{2}{*}{ Risk factor } & & \multicolumn{4}{|c|}{${ }^{\text {a }}$ ASF between } \\
\hline & & \multirow{2}{*}{$\begin{array}{l}\begin{array}{l}\mathrm{No}^{\mathrm{b}} \\
(\%)\end{array} \\
67\end{array}$} & \multirow{2}{*}{$\begin{array}{l}\begin{array}{l}\text { Yes }^{b} \\
(\%)\end{array} \\
0\end{array}$} & \multirow{2}{*}{$\begin{array}{l}\begin{array}{l}N A^{b} \\
(\%)\end{array} \\
33\end{array}$} & \multirow{2}{*}{$\begin{array}{l}\begin{array}{l}\text { Total } \\
(\mathrm{n})\end{array} \\
3\end{array}$} \\
\hline Awareness $^{c}$ & $\begin{array}{l}\text { Not aware } \\
\text { about ASF }\end{array}$ & & & & \\
\hline & $\begin{array}{l}\text { Aware about } \\
\text { ASF }\end{array}$ & 69 & 5 & 26 & 170 \\
\hline & $N A^{d}$ & 33 & 0 & 67 & 6 \\
\hline \multirow{3}{*}{$\begin{array}{l}\text { Biosecurity } \\
\text { measures }\end{array}$} & At least one & 70 & 3 & 28 & 40 \\
\hline & None & 68 & 6 & 27 & 127 \\
\hline & NA & 67 & 0 & 33 & 12 \\
\hline \multirow[t]{3}{*}{ Borrow boar } & No & 59 & 0 & 41 & 27 \\
\hline & Yes & 70 & 5 & 25 & 136 \\
\hline & NA & 69 & 8 & 23 & 13 \\
\hline \multirow[t]{3}{*}{ Breed } & Local & 67 & 4 & 28 & 67 \\
\hline & Improved & 69 & 5 & 26 & 111 \\
\hline & NA & 0 & 0 & 100 & 1 \\
\hline \multicolumn{6}{|l|}{$\begin{array}{l}\text { Duration of } \\
\text { enterprises }\end{array}$} \\
\hline & $\begin{array}{l}\text { Less or equal to } \\
10 \text { years }\end{array}$ & 67 & 3 & 30 & 112 \\
\hline & $\begin{array}{l}\text { Greater than } \\
10 \text { years }\end{array}$ & 74 & 6 & 20 & 50 \\
\hline & NA & 63 & 13 & 25 & 16 \\
\hline \multirow[t]{3}{*}{ Ectoparasites control } & No & 74 & 0 & 26 & 27 \\
\hline & Yes & 68 & 5 & 28 & 145 \\
\hline & NA & 57 & 14 & 29 & 7 \\
\hline \multirow[t]{3}{*}{ Feeding swill } & No & 72 & 9 & 19 & 47 \\
\hline & Yes & 68 & 3 & 29 & 130 \\
\hline & NA & 0 & 0 & 100 & 2 \\
\hline \multirow[t]{3}{*}{ Labour } & Family & 69 & 4 & 26 & 160 \\
\hline & Hired & 69 & 6 & 25 & 16 \\
\hline & NA & 0 & 0 & 100 & 3 \\
\hline \multirow[t]{3}{*}{ Pets present on farm } & No & 67 & 5 & 28 & 111 \\
\hline & Yes & 68 & 4 & 28 & 57 \\
\hline & NA & 82 & 0 & 18 & 11 \\
\hline \multirow[t]{3}{*}{ Piglets housing } & $\begin{array}{l}\text { Piglets housing } \\
\text { present }\end{array}$ & 69 & 5 & 25 & 91 \\
\hline & $\begin{array}{l}\text { Piglets not } \\
\text { housed }\end{array}$ & 71 & 2 & 27 & 83 \\
\hline & NA & 0 & 20 & 80 & 5 \\
\hline \multirow[t]{3}{*}{ Pigs housing } & $\begin{array}{l}\text { Pig housing } \\
\text { present }\end{array}$ & 66 & 5 & 29 & 111 \\
\hline & No pig housing & 75 & 0 & 25 & 64 \\
\hline & NA & 25 & 50 & 25 & 4 \\
\hline
\end{tabular}

Table 1 Risk factors for small-scale farms for ASF reports between first and second sampling ( $n=179), 2010-2011$ (Continued)

\begin{tabular}{|c|c|c|c|c|c|}
\hline \multirow[t]{3}{*}{ Replacement stock } & Own farm & 73 & 5 & 23 & 66 \\
\hline & $\begin{array}{l}\text { From neighbouring } \\
\text { farms }\end{array}$ & 67 & 4 & 29 & 106 \\
\hline & NA & 43 & 14 & 43 & 7 \\
\hline \multirow{3}{*}{$\begin{array}{l}\text { Wild pigs (bush pigs) } \\
\text { contact }\end{array}$} & No & 72 & 5 & 22 & 98 \\
\hline & Yes & 56 & 11 & 33 & 9 \\
\hline & NA & 64 & 3 & 33 & 72 \\
\hline
\end{tabular}

${ }^{a}$ ASF between- Reports of ASF on farms during the one year between the first and second sampling visits. This is the dependent variable and the row variables in the table are the independent variables

${ }^{b}$ The numbers in each of the cells under columns No, Yes and NA are relative proportions (percentages) of the total number of pigs (column Total, $n$ ) in each of the table rows

c Awareness encompasses those farms where farmers expressed having knowledge on the symptoms, spread, control and prevention measures for ASF

${ }^{d}$ Missing values

${ }^{\mathrm{e}}$ Biosecurity measures considered were presence of a fence to the farm, controlled entrance to the pig pens (presence of gate/door) and presence of foot baths

from which no disease had been reported [9-11, 16]. Although the importance of this finding is debated [1], it has raised concern of a role of long-term carriers, which would not be detected through clinical or serological surveillance, in the maintenance of the disease in endemically infected populations. In this study, we did not find any evidence supporting a role of long-term carriers. No PCR positive animals were detected during the first sampling, only a few during the second, and no antibody positive animals during either of the samplings. The two farms with PCR positive animals were both located in areas that had recently reported ASF outbreaks, and in one of them, the farmer reported having had deaths on the farm as a result of ASF just prior to our visit. The three PCR positive animals were seronegative and it is likely that the absence of seroconversion reflected sampling at an early stage of infection before clinical signs had developed and an antibody response had been mounted. A neighbouring farm also reported having had ASF outbreak at the second sampling, which may suggest possible spread from either of the two farms given the management practices and risk factors mentioned earlier.

A number of studies have shown that pigs that survive ASF, may have persisting infection, with detectable virus only in lymphoid tissues, and not in blood or serum, up to 2-3 months after infection [17-19]. Moreover, it has been demonstrated that pigs that survive infection have detectable levels of antibodies that persist for at least 1-2 years, with a half-life estimated at 1.8 years $[1,19,20]$. A scenario with persistent infection only in lymphoid tissues in seronegative pigs has not been described to our knowledge. In this study, no pigs were sacrificed, and therefore 
Table 2 Risk factors for medium-scale farms for ASF reports between first and second sampling $(n=49), 2010-2011$

\begin{tabular}{|c|c|c|c|c|c|}
\hline & & \multicolumn{4}{|c|}{${ }^{\mathrm{a}}$ ASF between } \\
\hline & & $\begin{array}{l}\mathrm{No}^{\mathrm{b}} \\
(\%)\end{array}$ & $\begin{array}{l}\text { Yes }^{b} \\
(\%)\end{array}$ & $\begin{array}{l}\mathrm{NA}^{\mathrm{b}} \\
(\%)\end{array}$ & $\begin{array}{l}\text { Total } \\
\text { (n) }\end{array}$ \\
\hline \multirow[t]{3}{*}{ Awareness $^{c}$} & $\begin{array}{l}\text { Not aware about } \\
\text { ASF }\end{array}$ & 50 & 0 & 50 & 2 \\
\hline & Aware about ASF & 85 & 4 & 11 & 46 \\
\hline & $N A^{d}$ & 100 & 0 & 0 & 1 \\
\hline \multirow[t]{3}{*}{ Biosecurity measures ${ }^{e}$} & At least one & 83 & 4 & 13 & 24 \\
\hline & None & 85 & 5 & 10 & 20 \\
\hline & NA & 80 & 0 & 20 & 5 \\
\hline \multirow[t]{3}{*}{ Borrow boar } & No & 100 & 0 & 0 & 17 \\
\hline & Yes & 78 & 4 & 19 & 27 \\
\hline & NA & 60 & 20 & 20 & 5 \\
\hline \multirow[t]{3}{*}{ Breed } & Local & 71 & 14 & 14 & 7 \\
\hline & Improved & 85 & 2 & 12 & 41 \\
\hline & NA & 100 & 0 & 0 & 1 \\
\hline
\end{tabular}

Duration of

enterprises

\begin{tabular}{|c|c|c|c|c|c|}
\hline & $\begin{array}{l}\text { Less or equal to } \\
10 \text { years }\end{array}$ & 85 & 3 & 12 & 34 \\
\hline & $\begin{array}{l}\text { Greater than } \\
10 \text { years }\end{array}$ & 75 & 8 & 17 & 12 \\
\hline & NA & 100 & 0 & 0 & 3 \\
\hline \multirow[t]{3}{*}{ Ectoparasites control } & No & 75 & 0 & 25 & 4 \\
\hline & Yes & 86 & 2 & 12 & 43 \\
\hline & NA & 50 & 50 & 0 & 2 \\
\hline \multirow[t]{3}{*}{ Feeding swill } & No & 88 & 6 & 6 & 17 \\
\hline & Yes & 81 & 3 & 16 & 32 \\
\hline & NA & 0 & 0 & 100 & 1 \\
\hline \multirow[t]{3}{*}{ Labour } & Family & 76 & 6 & 18 & 34 \\
\hline & Hired & 100 & 0 & 0 & 9 \\
\hline & NA & 100 & 0 & 0 & 6 \\
\hline \multirow[t]{3}{*}{ Pets present on farm } & No & 84 & 4 & 12 & 25 \\
\hline & Yes & 86 & 0 & 14 & 21 \\
\hline & NA & 67 & 33 & 0 & 3 \\
\hline \multirow[t]{3}{*}{ Piglets housing } & $\begin{array}{l}\text { Piglets housing } \\
\text { present }\end{array}$ & 80 & 5 & 15 & 40 \\
\hline & Piglets not housed & 100 & 0 & 0 & 8 \\
\hline & NA & 100 & 0 & 0 & 1 \\
\hline \multirow[t]{3}{*}{ Pig housing } & $\begin{array}{l}\text { Pig housing } \\
\text { present }\end{array}$ & 82 & 5 & 14 & 44 \\
\hline & No pig housing & 100 & 0 & 0 & 4 \\
\hline & NA & 100 & 0 & 0 & 1 \\
\hline \multirow[t]{3}{*}{ Replacement stock } & Own farm & 87 & 0 & 13 & 15 \\
\hline & $\begin{array}{l}\text { From } \\
\text { neighbouring farms }\end{array}$ & 82 & 6 & 12 & 33 \\
\hline & NA & 100 & 0 & 0 & 1 \\
\hline
\end{tabular}

Table 2 Risk factors for medium-scale farms for ASF reports between first and second sampling $(n=49), 2010-2011$ (Continued)

\begin{tabular}{llllll}
\hline $\begin{array}{l}\text { Wild pigs (bush pigs) } \\
\text { contact }\end{array}$ & No & 82 & 6 & 12 & 33 \\
& Yes & 100 & 0 & 0 & 1 \\
& NA & 87 & 0 & 13 & 15 \\
\hline
\end{tabular}

${ }^{\text {a }}$ ASF between- Reports of ASF on farms during the one year between the first and second sampling visits. This is the dependent variable and the row variables in the table are the independent variables

${ }^{b}$ The numbers in each of the cells under columns No, Yes and NA are relative proportions (percentages) of the total number of pigs (column Total, $n$ ) in each of the table rows

c Awareness as a variable encompasses those farms where farmers expressed having knowledge on the symptoms, spread, control and prevention measures for ASF

${ }^{d}$ Missing values

e Biosecurity measures considered were presence of a fence to the farm, controlled entrance to the pig pens (presence of gate/door) and presence of foot baths

lymphoid or other tissues could not be tested, but because no antibody positive pigs were found, we do not believe this has affected our results.

To confirm that any positive animals found during the first sampling were persistently positive, as would be expected from long-term carriers, our ambition was to resample the same animals during the second sampling round. This was in many cases not possible. However, given that no animals were positive, neither on PCR nor on ELISA, during the first sampling round, and only three were PCR positive during the second (all closely linked with outbreaks directly affecting study farms), this did not affect the interpretation of our results nor the conclusion regarding presence or absence of potential long-term carriers in the study population.

The absence of detectable seropositivity in the study population is in accordance with several studies suggesting a very low seroprevalence of ASF in domestic pig populations in eastern Africa [21, 22]. The low seroprevalence, in spite of a relatively high incidence of ASF, reflects circulation of a highly virulent strain of ASFV with high mortality, but is likely also a result of the common practice of selling off pigs for slaughter as soon as an outbreak of ASF occurs, to salvage some income from the dying or in-contact pigs [1, 22]. A recent publication from Uganda, however, presents results from a combined slaughterhouse and on-farm study with sampling of apparently healthy pigs and reports a seroprevalence of above $50 \%$, indicating circulation of low virulent viruses and possibly development of natural resistance [12]. This is in vast contrast not only to our results, but also to those from the several other published studies from the region [10, 16, 21, 22]. The serological analyses in the aforementioned study [12], however, were performed using an in-house ELISA based on the semipurified ASFV antigen. This method is known 
Table 3 Univariable logistic regression model on pig farms for ASF reports between the samplings $(n=233), 2010-2011$

\begin{tabular}{|c|c|c|c|c|}
\hline \multirow{2}{*}{ Independent variables } & & \multicolumn{3}{|c|}{ ASF between } \\
\hline & & $\overline{\mathrm{OR}}$ & $95 \% \mathrm{Cl}$ & $P$-value \\
\hline \multirow[t]{2}{*}{ Awareness $^{a}$} & Not aware about ASF & 1 & & \\
\hline & Aware about ASF & - & - & - \\
\hline \multirow[t]{2}{*}{ Biosecurity measures ${ }^{b}$} & None & 1 & & \\
\hline & At least one & 1.01 & $(0.26 ; 3.37)$ & 0.99 \\
\hline \multirow[t]{2}{*}{ Borrow boar } & No & 1 & & \\
\hline & Yes & - & - & - \\
\hline \multirow[t]{2}{*}{ Breed } & Local & 1 & & \\
\hline & Improved & 0.92 & $(0.28 ; 3.57)$ & 0.90 \\
\hline \multicolumn{5}{|l|}{ Duration of enterprise } \\
\hline & Less or equal to 10 years & 1 & & \\
\hline & Greater than 10 years & 2.28 & $(0.61 ; 8.55)$ & 0.21 \\
\hline \multirow[t]{2}{*}{ Ectoparasites control } & No & 1 & & \\
\hline & Yes & - & - & 0.99 \\
\hline \multirow[t]{2}{*}{ Farm size } & Small-scale & 1 & & \\
\hline & Medium-scale & 2.16 & $(0.61 ; 7.15)$ & 0.21 \\
\hline \multirow[t]{2}{*}{ Feeding swill } & No & 1 & & \\
\hline & Yes & 0.66 & $(0.20 ; 2.31)$ & 0.49 \\
\hline \multirow[t]{2}{*}{ Labour } & Family & 1 & & \\
\hline & Hired & 1.78 & $(0.38 ; 6.45)$ & 0.41 \\
\hline \multirow[t]{2}{*}{ Pets present on farm } & No & 1 & & \\
\hline & Yes & 0.64 & $(0.14 ; 2.33)$ & 0.53 \\
\hline \multirow[t]{2}{*}{ Piglets housing } & Piglets housing present & 1 & & \\
\hline & Piglets not housed & 1.87 & $(0.52 ; 8.77)$ & 0.37 \\
\hline \multirow[t]{2}{*}{ Pig housing } & Pig housing present & 1 & & \\
\hline & No pig housing & - & - & 0.99 \\
\hline \multirow[t]{2}{*}{ Replacement stock } & From own stock & 1 & & \\
\hline & From neighboring farms & 1.63 & $(0.45 ; 7.64)$ & 0.49 \\
\hline \multirow[t]{2}{*}{ Wild pigs (bush pigs) contact } & No & 1 & & \\
\hline & Yes & 2.04 & $(0.10 ; 14.19)$ & 0.53 \\
\hline
\end{tabular}

ASF between - Reports of ASF on farms during the one year between the first and second sampling visits

$O R$ odds tatio, $\mathrm{Cl}$ confidence interval, ASF African swine fever

- indicates that the model was inestimable because of skewed data

${ }^{a}$ Awareness as a variable encompasses those farms where farmers expressed having knowledge on the symptoms, spread, control and prevention measures for ASF

${ }^{\mathrm{b}}$ Biosecurity measures considered were presence of a fence to the farm, controlled entrance to the pig pens (presence of gate/door) and presence of foot baths

to give a certain proportion of false positive test results, especially with poorly preserved samples as is often the case under African conditions due to the hot climate and not always functioning cold chain. Therefore, unexpected positive results, such as in this case, should always be confirmed using an alternative test before conclusions can be drawn from the results $[23,24]$.

The vast majority of pig farms included in the study were small-scale $(78.7 \%)$ with a maximum of ten pigs while medium-scale farms (11-200 pigs) accounted for only $21.3 \%$. There were high proportions of farms with pigs and piglets that were not housed. There were differences in the relative importance of risk factors and the extent of use of biosecurity measures between medium-scale and small-scale farms (Tables 1 and 2). This difference in distribution of ASF risk factors and biosecurity measures between the two categories of farms agrees with the findings reported by Costard et al [25] in an earlier study in Madagascar. On both 
categories of small and medium-scale farms, farmers reported improper disposal of carcasses which included selling of dead/dying pigs for slaughter, throwing carcasses in bushes and giving pork from diseased pigs to neighbours (data not shown). These practices will certainly promote the spread of ASF through movement of the infected pigs, contaminated carcasses and pork products especially during ASF outbreaks. None of the risk factors were, however, significantly associated with ASF outbreaks between the two visits, probably partly due to low power of the study, imprecise identifications of the risk factors, and to some extent missing values (NA). However, the proportion of missing values was usually low (below $10 \%$ ), except for the question on contacts with wild pigs, and we believe that the missing answers would be non-differential thus only leading to a bias towards the null hypothesis.

\section{Conclusions}

Our results indicate a high incidence rate of ASF in the study area, and demonstrate that long-term carriers are not needed to explain the maintenance of the disease in the population. Potential ASF risk factors were present on both small and medium-scale pig farms, although small-scale farms exhibited a higher proportion with multiple potential risk factors and lacking any implementation of biosecurity measures. However, no risk factors were significantly associated with ASF reports during the study.

\section{Methods}

\section{Study area and farm selection}

A longitudinal study was carried out in the districts of Masaka and Rakai in central Uganda (Fig. 1). A total of 24 sub-counties were selected by targeting sub-counties with the largest number of pig farms as indicated by the district veterinary officers. A sampling frame of villages within selected sub-counties was generated, and five villages were randomly selected per sub-county. Two farmers within each of these villages were selected in consultation with the district veterinary officers. In some cases, the veterinary officers suggested new villages as replacements based on unavailability of pigs in some of the originally selected villages. A farm was only included in the sample if the farmer affirmed that he/she planned to keep pigs for the next one year and if the farm reared at least three pigs. The farms were visited twice, during June to October 2010 and during March to June 2011. All farms were geo-referenced (Fig. 1).

\section{Data collection}

Information was collected using a questionnaire with closed and open-ended questions, after getting informed consent. The questionnaire was initially discussed with the local veterinary personnel to make sure they all understood the questions similarly since they had to be translated into Luganda, the local language. The enumerators made sure that the questions were understood by the respondents. During the first visit, farmer awareness and knowledge of ASF was investigated. Also, the farmers were asked whether their pigs had had any incidences of infectious disease with clinical signs suggestive of ASF (that is mortality, fever, loss of appetite, reddened skin) on their farm in the previous 1-2 years. In addition, information on management practices, biosecurity measures and general information on the farms were taken (Tables 1 and 2). During the second visit, the farmers were asked specifically if they had had outbreaks of ASF since the previous visit and also to describe the outcome of these outbreaks in terms of clinical signs and mortality.

\section{Sample collection}

Permission was sought to sample three pigs from farms where interviews were conducted. Three pigs were chosen from each herd, restrained by the muzzle using a commercially available pig catcher and examined by a veterinarian. All the pigs sampled were at least three months of age. Sampling was done twice on the pig farms (i.e. at each visit at time periods as indicated above), with an ambition of including the same pigs in the two samplings. This, however, was in many cases not possible, because pigs had been sold or had died or the farmers could not be found at the time of the second sampling. Whole blood was taken from the jugular vein into appropriate vacutainers. Serum samples were similarly collected from each pig into appropriate serum vacutainers (BD, New Jersey). Whole blood was aliquoted into duplicate $2 \mathrm{ml}$ cryovials (Cryo.s, Greiner Bio-one, Wemmel). Serum tubes were centrifuged at $2000 \mathrm{~g}$ for 10 mins to separate serum from clotted blood serum aliquoted into duplicate $2 \mathrm{ml}$ cryovials. The aliquoting and centrifugation were done at the regional district laboratories every evening after farm visits. The duplicate cryovials were later transported on ice in cool boxes to the Molecular Genetics Laboratory in the College of Agriculture and Environmental Sciences, Makerere University for storage at $-20^{\circ} \mathrm{C}$ and $-80{ }^{\circ} \mathrm{C}$ as working and long-term storage sample aliquots, respectively.

All handling of animals including sampling was carried out, or overseen, by District Veterinary office staff in accordance with their national mandate. The district veterinary office, under the Ministry of Agriculture Animal Industry and Fisheries (MAAIF) has the official mandate to carry out investigations related to animal disease in the country. 


\section{ASFV DNA detection}

In order to check for the presence of ASFV nucleic acids, the samples were prepared for total DNA extraction. One hundred microlitres of anticoagulated blood from each pig sample for the three pigs per farm was collectively pooled and thoroughly mixed to make $300 \mu \mathrm{l}$. From this pool, $100 \mu \mathrm{l}$ was used for total genomic DNA extraction using the DNeasy Blood \& Tissue kit (Qiagen, Duesseldorf) following the manufacturer's protocol. In all extraction steps, a negative control was included. The extracted DNA was either immediately used in the RT-PCR assay, or stored at $-20{ }^{\circ} \mathrm{C}$ until used. For the detection of ASFV DNA, a commercially available ASF RT-PCR Tetracore ${ }^{\oplus}$ assay (Tetracore Inc., Rockville, Maryland) was used according to the instructions of the manufacturer. The assay was optimized for use on a SmartCycler ${ }^{\ominus}$ (Cepheid Inc., Sunnyvale, California), a $10 \mathrm{~kg}$ portable instrument that is operated by a laptop computer [26].

For the pooled samples that tested positive, the entire procedure from DNA extraction to RT-PCR was repeated for individual pig blood samples to identify which of the three pigs was actually positive.

\section{ASFV antibody detection}

For the detection of antibodies against ASFV, a commercially available blocking ELISA (INGEZIM PPA Compac 11.PPA.K3, INGENASA, Spain), recommended by the OIE, was used in accordance with instructions from the manufacturer. It targets the VP73 viral protein and is reported to have a sensitivity and specificity of 95-98\% [27]. The positive and doubtful samples were re-tested for confirmation using the same INGENASA ELISA and the recently released SVANOVIR ${ }^{\circ}$ ASFV-Ab (Boehringer Ingelheim Svanova, Uppsala, Sweden) indirect ELISA. The SVANOVIR ${ }^{\circledR}$ ASFV-Ab ELISA kit (screening plates) was used according to the instructions by the manufacturer.

\section{Differential diagnosis}

To reduce the risk of misclassification, a subset of the samples from the first sampling round was also tested for classical swine fever, the most important differential diagnosis to ASF. In addition, the same subset was tested for presence of porcine reproductive and respiratory syndrome (PRRS) virus, which in its most virulent form can cause a disease with clinical signs resembling ASF. For antibody detection, commercial ELISA kits were used (CSF Ab test and PRRS X3 antibody test, IDEXX Laboratories Inc., Maine, USA). For virus detection, commercially available CSF and PRRS RT-PCR kits were used (Tetracore Inc., Rockville, Maryland). All tests were run according to the instructions by the manufacturers.

\section{Statistical analysis}

Incidence rates for ASF in the study population were estimated based on the farmer reports of outbreaks 1-2 years prior to first sampling (ASF prior; 1.5 years taken as denominator) and of outbreaks between first and second sampling (ASF between; 1 year as denominator), respectively. A case was defined as a herd with a reported outbreak during the period of interest of an infectious disease with clinical signs suggestive of ASF, i.e. high mortality, high fever and loss of appetite, with or without discoloration of the skin, diarrhea, abortions etc.

A test of whether the two incidence estimates were significantly different was computed in R. Logistic regression models were used to assess the association between reports of outbreaks during the period of interest of an infectious disease with clinical signs suggestive of ASF (response variable) and management practices (independent variables). In this analysis, only outbreaks that occurred between first and second sampling were considered. None of the risk factors were associated with the response variable $(P>0.25)$ and no multivariable model was therefore attempted. Data was analysed using $\mathrm{R}$ statistical package (Version 2.15.2) for logistic regressions [28]. In this study, the farms were grouped into two categories basing on the number of pigs reared. They included; small-scale (1-10 pigs) and medium-scale pig farms (11-200 pigs).

Positive and negative test results based on RT-PCR and ELISA were entered into a Microsoft Excel spreadsheet (Microsoft Corporation, Redmond, Washington). Apparent and true prevalence were computed using epiR package in $\mathrm{R}$ (Version 2.15.3) and as earlier described [29] using sensitivity and specificity of 90 and $100 \%$ respectively [26].

\section{Abbreviations}

ASF: African swine fever; ASFV: African swine fever virus; CSF: Classical swine fever; Ct: Cycle threshold; DNA: Deoxyribonucleic acid; ELISA:: Enzyme-linked immunosorbent assay; PCR: Polymerase chain reaction; PRRS: Porcine reproductive and respiratory syndrome; RT-PCR: Real time polymerase chain reaction.

Competing interests

The authors declare that they have no competing interests.

\section{Authors' contributions}

DM contributed to the conception of the idea, data collection, data analysis, laboratory studies, drafting and writing of the manuscript. CM contributed to data collection, laboratory studies and manuscript preparation. UE

contributed to conception of the idea, data analysis and drafting of the manuscript. SB contributed to conception of the idea and writing of the manuscript. LM contributed to conception of the idea, design of the study and data collection and writing of the manuscript. ROA contributed to conception of the idea, data collection and writing of the manuscript. RPB contributed to conception of the idea, design and writing of the manuscript. $\mathrm{MO}$ contributed to conception of the idea and writing of the manuscript. $\mathrm{MB}$ contributed to conception of the idea, design and writing of the manuscript. KS contributed to the conception of the idea, data collection, 
data analysis, laboratory studies, drafting and writing of the manuscript. All authors read and approved the final manuscript.

\section{Authors' information}

DM is a PhD holder (formerly PhD student) who worked with this team as part of his doctoral studies and is a researcher at Makerere University. CM is associate professor and researcher at Makerere University and has sufficiently researched on livestock diseases. UE is a Professor of veterinary epidemiology. SB has research interest in livestock diseases and veterinary public health and is associate professor at Swedish University of Agricultural Sciences (SLU). LM is a senior veterinary officer working under MAAIF and is conversant with ASF occurrence in the study area. ROA is senior veterinary officer at MAAIF's National Diseases Diagnostic Centre (NADDEC)'s laboratory, Uganda's livestock diseases diagnostic center. RPB is a researcher under International Livestock Research Institute (ILRI) and has previously researched on ASF in eastern Africa. MO is a professor of veterinary medicine with research interests in tick-borne diseases in both domestic animals and wildlife. MB is a professor of veterinary virology based at SLU. KS is associate professor and deputy state epizootiologist at the National Veterinary Institute (SVA) in Uppsala, Sweden, with expertise in infectious diseases epidemiology and disease control.

\section{Acknowledgements}

We acknowledge the Swedish research council FORMAS (Grant No. 221-2009-1984) and the Swedish international development cooperation agency, Sida (Grant No. 75007369) through the Embassy of Sweden in Kampala under the framework of Sida-Mak bilateral research support program phase 3 to the vet sub-program (awarded in 2010) who provided the financial support for this study. We also acknowledge the contribution from our collaborating institutions like Swedish University of Agricultural Sciences (SLU), National Veterinary Institute (SVA), International Livestock Research Institute (ILRI), Makerere University, and MAAIF in Uganda. Our gratitude also goes to Ms. Susan Ndyanabo who assisted in running some experiments at the molecular genetics laboratory, College of Agriculture and Environmental Sciences, Makerere University and to all the field veterinarians in Masaka and Rakai, who worked with us in collecting samples and data for this study.

\section{Author details}

${ }^{1}$ Department of Wildlife and Aquatic Resources, College of Veterinary Medicine, Animal Resources and Biosecurity, Makerere University, P. O. Box 7062, Kampala, Uganda. ${ }^{2}$ Department of Biological Sciences, College of Natural Sciences, Makerere University, P. O. Box 7062, Kampala, Uganda. ${ }^{3}$ Department of Clinical Sciences, Swedish University of Agricultural Sciences, P. O. Box 7054, SE-750 07 Uppsala, Sweden. ${ }^{4}$ Department of Biomedical Sciences and Veterinary Public Health, Swedish University of Agricultural Sciences, P. O. Box 7028, SE-750 07 Uppsala, Sweden. ${ }^{5}$ District Veterinary Office, under the Ministry of Agriculture, Animal Industry and Fisheries, Masaka, Uganda. ${ }^{6}$ Ministry of Agriculture, Animal Industry and Fisheries, P. O. Box 102, Entebbe, Uganda. ${ }^{7}$ International Livestock Research Institute (ILRI), P.O. Box 30709, GPO 00100 Nairobi, Kenya. ${ }^{8}$ Department of Disease Control and Epidemiology, National Veterinary Institute (SVA), SE-751 89 Uppsala, Sweden.

\section{Received: 2 September 2014 Accepted: 5 May 2015}

\section{Published online: 13 May 2015}

\section{References}

1. Penrith ML, Vosloo W, Jori F, Bastos ADS. African swine fever virus eradication in Africa. Virus Res. 2013;173:228-46.

2. FAO. FAO takes a close look at the threat of African swine fever introduction into Eastern Europe. In: EMPRES Transboundary Animal Diseases Bulletin. vol. 36. Rome, FAO (available at http://www.fao.org/ docrep/013/i1958e/i1958e00.pdf) 2010.

3. FAOSTAT: [http://faostat3.fao.org/home/index.html]. 2011.

4. Kagira J, Kanyari PN, Maingi N, Githigia S, Ng'ang'a JC, Karuga J. Characteristics of the smallholder free-range pig production system in western Kenya. Trop Anim Health Prod. 2010;42(5):865-73.

5. FAO. African Swine Fever (ASF) Recent developments and timely updates Worrisome dynamics: Steady spread towards unaffected areas could have disastrous impact. In. Edited by Focus on No. 6 [electronic bulletin]. Rome, FAO (available at http://www.fao.org/docrep/016/ap372e/ap372e.pdf); 2012.

6. Sánchez-Vizcaíno JM, Arias M. African Swine fever virus. In: Zimmerman JJ, Karriker LA, Ramirez A, Schwartz KJ, Stevenson GW, editors. Diseases of swine. 10th ed. Ames, lowa: Blackwell Publishing Professional; 2012. p. 396-404.

7. Penrith ML, Thomson GR, Bastos ADS. African swine fever. In: Coetzer JAW, Tustin RC, editors. Infectious diseases of livestock with special reference to Southern Africa. Cape Town: Oxford University Press; 2004. p. 1087-119.

8. Jori F, Vial L, Penrith ML, Pérez-Sánchez R, Etter E, Albina E, et al. Review of the sylvatic cycle of African swine fever in sub-Saharan Africa and the Indian Ocean. Virus Res. 2013;173(1):212-27.

9. Owolodun OA, Obishakin ET, Ekong PS, Yakubu B. Investigation of African swine fever in slaughtered pigs, Plateau state, Nigeria, 2004-2006. Trop Anim Health Prod. 2010;42(8):1605-10.

10. Gallardo C, Okoth E, Pelayo V, Anchuelo R, Martı́n E, Simo' n A, et al. African swine fever viruses with two different genotypes, both of which occur in domestic pigs, are associated with ticks and adult warthogs, respectively, at a single geographical site. J Gen Virol. 2011;92:432-44.

11. Fasina FO, Shamaki D, Makinde AA, Lombin LH, Lazarus DD, Rufai SA, et al. Surveillance for African swine fever in Nigeria, 2006-2009. Transbound Emerg Dis. 2010;57:244-53.

12. Atuhaire DK, Afayoa M, Ochwo S, Mwesigwa S, Mwiine FN, Okuni JB, et al. Prevalence of African swine fever virus in apparently healthy domestic pigs in Uganda. BMC Vet Res. 2013;9:263.

13. Andersson M. African swine fever in Uganda- description of a recent outbreak and studies of possible differential diagnoses. Uppsala, Sweden: Swedish University of Agricultural Sciences; 2011. Retrieved from http:// stud.epsilon.slu.se/2407/1/andersson_m_110401.pdf.

14. Muhanguzi D, Lutwama V, Mwiine FN. Factors that influence pig production in Central Uganda - Case study of Nangabo Sub-County. Wakiso district Vet World. 2012;5(6):346-51.

15. OIE: WAHID interface animal health information [http://www.oie.int/wahis_2/ public/wahid.php/Diseaseinformation/Diseasedistributionmap]. 2014.

16. Okoth E, Gallardo C, Macharia JM, Omore A, Pelayo V, Bulimo DW, et al. Comparison of African swine fever virus prevalence and risk in two contrasting pig-farming systems in South-West and Central Kenya. Prev Vet Med. 2013;110(2):198-205.

17. Wilkinson PJ. The persistence of African swine fever in Africa and the Mediterranean. Prev Vet Med. 1984;2:71-82.

18. de Carvalho Ferreira HC, Weesendorp E, Elbers AR, Bouma A, Quak S, Stegeman JA, et al. African swine fever virus excretion patterns in persistently infected animals: a quantitative approach. Vet Microbiol. 2012;160(3-4):327-40.

19. Penrith ML, Thomson GR, Bastos AD, Phiri OC, Lubisi BA, Du Plessis EC, et al. An investigation into natural resistance to African swine fever in domestic pigs from an endemic area in Southern Africa. Rev Sci Tech. 2004;23(3):965-77.

20. Sanchez Botija C. Peste Porcina Africana- Nuevos desarollos. Rev sci tech Off int Epiz. 1982;1(4):991-1029.

21. Gallardo C, Ademun AR, Nieto R, Nantima N, Arias M, Martín E, et al. Genotyping of African swine fever virus (ASFV) isolates associated with disease outbreaks in Uganda in 2007. Afr J Biotechnol. 2011;10(17):3488-97.

22. Muwonge A, Munang'andu HM, Kankya C, Biffa D, Oura C, Skjerve E, et al. African swine fever among slaughter pigs in Mubende district, Uganda. Trop Anim Health Prod. 2012;44:1593-8.

23. OIE. African swine fever. In: Manual of diagnostic tests and vaccines for terrestrial animals (mammals, birds and bees). Chapter 2.8.1. Paris, France: World Organisation for Animal Health; 2012.

24. Cubillos C, Gómez-Sebastian S, Moreno N, Nuñez MC, Mulumba-Mfumu LK, Quembo CJ, et al. African swine fever virus serodiagnosis: a general review with a focus on the analyses of African serum samples. Virus Res. 2013;173(1):159-67.

25. Costard S, Porphyre V, Messad S, Rakotondrahanta S, Vidon H, Roger F, et al. Multivariate analysis of management and biosecurity practices in smallholder pig farms in Madagascar. Prev Vet Med. 2009;92(3):199-209.

26. Zsak L, Borca MV, Risatti GR, Zsak A, French RA, Lu Z, et al. Preclinical diagnosis of African swine fever in contact-exposed swine by a real-time PCR assay. J Clin Microbiol. 2005;43(1):112-9.

27. Etter EMC, Seck I, Grosbois V, Jori F, Blanco E, Vial L, et al. Seroprevalence of African Swine Fever in Senegal, 2006. Emerg Infect Dis. 2011;17:1. 
28. R Core Team. R: A Language and Environment for Statistical Computing In. Edited by R Foundation for Statistical Computing. Vienna, Austria: R Foundation for Statistical Computing; ISBN 3-900051-07-0; http://www. R-project.org/; 2012.

29. Reiczigel J, Földi J, Ózsvári L. Exact confidence limits for prevalence of a disease with an imperfect diagnostic test. Epidemiol Infect. 2010;138(11):1674-8.

Submit your next manuscript to BioMed Central and take full advantage of:

- Convenient online submission

- Thorough peer review

- No space constraints or color figure charges

- Immediate publication on acceptance

- Inclusion in PubMed, CAS, Scopus and Google Scholar

- Research which is freely available for redistribution 